Epidemiology

\title{
Outdoor Fitness Zone: utilization pattern, and environmental and individual characteristics associated with the volume of utilization
}

\author{
Debora Bernardo da Silva ${ }^{1}$ (D), Emerson Sebastião ${ }^{2}$ (D), Thiago Ferreira de Sousa ${ }^{3}$ (D), \\ Sheilla Tribess ${ }^{4}$ (D), Camila Bosquiero Papini ${ }^{4}$ \\ ${ }^{1}$ Universidade de São Paulo, Faculdade de Saúde Pública, São Paulo, SP, Brazil. ${ }^{2}$ Northern \\ Illinois University, Departamento of Kinesiology and Physical Education, Dekalb, IL, United \\ States. ${ }^{3}$ Universidade Federal do Recôncavo da Bahia, Amargosa, BA, Brazil. ${ }^{4}$ Universidade \\ Federal do Triângulo Mineiro, Departamento de Ciências do Esporte, Uberaba, MG, Brazil.
}

Associate Editor: Danilo Rodrigues Pereira da Silva, Universidade Federal de Sergipe, São

Cristóvão, SE, Brazil.

\begin{abstract}
Aim: To examine the association between environmental and individual characteristics and utilization pattern of Outdoor Fitness Zones (OFZ) with the volume of utilization of these public spaces in Uberaba, Brazil. Methods: Cross-sectional descriptive study. Data collection was conducted using "in loco" interviews (three different days and times) and direct observation of nine OFZ. Poisson regression analysis was used to estimate prevalence ratios using the volume of utilization higher than 90 min per week as the dependent variable and a collection of socio-demographic, environmental, utilization pattern, and OFZ characteristics as independent variables. Results: Adjusted analysis revealed that volume of utilization higher than $90 \mathrm{~min}$ per week of OFZ was associated with a higher prevalence ratio among users utilizing such spaces to meet friends sometimes $(\mathrm{PR}=2.43 ; 1.21-4.90)$ and always $(\mathrm{PR}=3.43 ; 1.61-7.34)$ compared to not meeting friends. A lower prevalence ratio was found in users who attend the OFZ only during the week or only weekend days $(\mathrm{PR}=0.52 ; 0.37-0.73$ ) compared to a user who attends both (week and weekends days). OFZ not providing a space for walking or jogging $(\mathrm{PR}=0.48 ; 0.23-0.99)$ were also associated with a lower prevalence ratio of utilization higher than 90 min per week. Conclusions: The findings demonstrated that most individual and environmental characteristics and utilization patterns of the OFZ in the city of Uberaba, MG, Brazil, were not associated with the volume of utilization. Users who meet friends and attend both week and weekend days OFZ that features walking or running trails were associated with a higher volume of utilization.
\end{abstract}

Keywords: physical activity, health promotion, built environment, epidemiology.

\section{Introduction}

Physical inactivity is a global public health challenge ${ }^{1}$. Despite increasing efforts to promote physical activity in different populations, a significant amount of the world's population does not reach the minimum amount of recommended physical activity per week ${ }^{2}$, from 150-300 min of moderate physical activity, to promote health benefits in adults $^{3}$. There is compelling evidence of the association between a physically inactive lifestyle and an increased risk for a large array of adverse health outcomes including, but not limited to, chronic diseases such as cardiovascular diseases, type 2 diabetes, and some types of cancer ${ }^{4}$. These conditions account for over five million deaths per year ${ }^{5}$. In addition to the increased risk for morbidity and premature death, physical inactivity is responsible for a substantial economic burden in society ${ }^{4}$.

Among the important ways to promote a physically active lifestyle, the use of ecological frameworks con- stitutes a significant approach to promote physically active behavior. This is because ecological models consider the influence of multiple levels of determinants such as interand intrapersonal, social, organizational, policy, and environmental (natural and built) factors that have a strong relationship with physical activity participation ${ }^{6}$. The outdoor fitness zones (OFZs) installed in public areas (i.e., normally parks) are equipped with gymnastics apparatus developed to improve the flexibility, joint mobility, muscle strength, and cardiorespiratory capacity of users; and are characterized as a space available for the population to engage in free of cost, outdoor physical activity ${ }^{7,8}$. In Curitiba, a city in the Southeast of Brazil, it was observed that the pattern of use and the physical activity level of the users may vary according to the income of the neighborhood in which the OFZ is located ${ }^{9}$, while in a different study conducted in the South of Brazil, women and lowincome individuals reported higher use of OFZs for physical activity purposes. These findings highlight the impor- 
tance of such facilities in helping to reduce social inequities related to leisure-time physical activity ${ }^{10}$. It seems that OFZs contribute to increasing the physical activity level of users and attracting new users. Researchers have pointed out that the number of devices, the presence of shade, accessibility, and other services offered have a positive influence on the use of these places. It is further believed that OFZs installed in green areas and offering more sports/exercise amenities will have a higher volume of users ${ }^{11}$.

Although important, previous studies were conducted in different regions of Brazil, which limits their generalizability to other parts of the country. Furthermore, previous studies did not take into account more specific characteristics of the environment that may influence the utilization of the OFZ. Therefore, it remains unclear in the literature whether environmental features present an association with OFZ utilization. Although the OFZ may be considered a strategy to facilitate physical activity, more broad and specific aspects of the environment (i.e., natural or built) such as increase information and signs about the equipment and how to use it, facilitators (i.e., presence of an exercise specialist) and improve the quality and maintenance of both the equipment and the physical environment in the park around the equipment. ${ }^{12}$.

To this end, the present study aimed to examine the association between environmental and individual characteristics as well as the pattern of utilization of OFZs within the volume of utilization of these spaces in the city of Uberaba, Brazil. Based on previous studies conducted with a similar purpose, we hypothesized that environmental and individual characteristics, as well as the utilization pattern of the OFZ, would be significantly associated with the volume of utilization of these public spaces.

\section{Methods}

\section{Study location and ethical care}

This cross-sectional descriptive study was conducted in nine OFZs in Uberaba-MG, Brazil. The city of Uberaba is located in the microregion of the "Triangulo Mineiro" about $483 \mathrm{~km}$ from the capital Belo Horizonte ${ }^{13}$ and is considered a midsize city. According to the 2010 census, the city of Uberaba has approximately 296,000 inhabitants with a demographic density of 65.43 inhabitants $/ \mathrm{km}^{2}$ and a Human Development Index (HDI) of $0.772^{13}$. The present research protocol was approved by the Institution Review Board of the University of Uberaba (process number: 2.010.753, CAAE 65389417.0.0000.5145) and all participants signed informed consent before the start of data collection.

\section{Selection of outdoor fitness zones (OFZs)}

To identify the correct number of existing OFZs, two lists containing the addresses of the OFZs in the city were obtained. One list was obtained from the Sports and Leisure Foundation of the municipality and the second was from the City Hall of Uberaba, MG. The two lists were unified to provide a total of 51 OFZs. After verification of each OFZ by a researcher, seven OFZs were excluded as they were not found at the indicated address, and six were due to an incomplete address. Thus, the total number of OFZs available in Uberaba is 38 .

For the purpose of this study, of the total number of OFZs, $20 \%$ (i.e., $\mathrm{n}=8$ ) were estimated for visitation and data collection. This is in accordance with the procedures conducted by Souza et al. $(2014)^{8}$. The OFZs were distributed on an Excel spreadsheet in alphabetical order and a reference code was attributed to each (1 to 38). Using a different Excel spreadsheet, a number was attributed to each reference code (1 to 38) using the Excel random function. In the second step, the random numbers were sorted from lowest to highest and the first number of the corresponding code was used for the systematic draw of the OFZ; jumping every five to define the OFZs to be included in the study. Thus, eight OFZs were drawn and one was chosen by convenience (i.e., OFZ "Parque das Acácias"). This yielded a total of nine OFZs included in the study. The OFZ "Parque das Acácias" was selected by convenience due to its popularity among residents. This OFZ is located in a park that receives approximately 20,000 visitors per month ${ }^{14}$.

\section{Selection of participants and data collection}

At the OFZ, the users were selected by convenience as long as they met the following inclusion criteria: a) participation in any type of physical activity in the OFZ on the scheduled day/time for data collection and; b) aged 18 years and older. There was no limit on the number of users that could be interviewed at each OFZ. Four interviewers were selected to conduct all the interviews and observations at the OFZs. All interviewers received four hours of training (i.e., theoretical and practical) on the data collection instruments, inclusion criteria, and how to approach potential participants (i.e., OFZ users). The interviewers were further instructed to remain at the OFZ throughout the time scheduled, even if the OFZ was not being used.

Data collection occurred on three different days at each OFZ (i.e., two weekdays and one weekend day) and at three different times of day (i.e., early morning: 7.009.00 AM; late morning: 11.00 AM-Noon; evening: 5.007.00 PM). If it was raining or if it was a holiday on the day that data collection was scheduled, data collection was conducted on the following day. Data collection was conducted between September and November of 2017. 
The questionnaire administered was specifically developed for this study and was separated into three sections: a) Sociodemographic information (i.e., age, sex, income, number of children, marital status, education attainment, diagnosed chronic diseases, and perceived health); b) OFZ utilization (i.e., attending accompanied, meeting friends, meeting new people, days attended, how long using the OFZ, proximity to residence, accessibility, safety, and presence of an exercise specialist) based on the study conducted by Souza et al. $(2014)^{8}$; and c) Leisuretime physical activity - assessed using section four of the International Physical Activity Questionnaire (IPAQ), long version ${ }^{15}$.

The IPAQ (i.e., section four) was used to estimate the weekly physical activity level during leisure time of the OFZ users.

Weekly leisure-time physical activity level was calculated considering frequency vs. min and adopting the following formula ${ }^{15}$ :

$$
W+\operatorname{Mod}+2 \times \operatorname{Vig}
$$

where $W=$ walking; $M o d=$ moderate-intensity physical activity; Vig = vigorous-intensity physical activity.

The interviewers performed direct observation to characterize the built environment of the OFZ, using a script that took into account the following factors: number of pieces of equipment and their level of conservation, availability of a general instruction panel on how to use the equipment, availability of a parking lot or a facility to park the car/motorcycle, type of area (i.e., commercial or residential), lighting, trees and shade, other options for physical activity engagement (e.g., sports courts, track). The questions to characterize the environment were based on the questionnaire developed and employed by Parra et al. $(2010)^{16}$.

\section{Dependent variable}

The dependent variable of this study was the weekly volume of utilization of the OFZ (mean \pm standard deviation: $105.8 \pm 53.1$; range $12-160 \mathrm{~min}$ ). The median value was used as the cut-point to create the dependent variable (i.e., higher than 90 min per week). To compute the volume of utilization of the OFZ, the frequency multiplied by the time spent in the OFZ reported by the users in a week was considered.

\section{Independent variables}

Individual variables: sex (male or female), age $(<45,46$ to 60 , or $>60)$, marital status (single, married, widow, divorced, or living with a partner), children (yes or no), education attainment (none or elementary incomplete, elementary complete, high school incomplete, high school graduate, some college, college degree), income (up to 1 , more than 1 and up to 2 , more than 2 and up to 5 , more than 5 and up to 10 minimum wages), diagnosed chronic diseases (yes or no), perceived health (excellent, very good, or good), leisure-time physical activity (physically active or insufficiently active), physical activity engagement before the OFZ (yes or no), and mode of transportation (active or passive).

Utilization pattern of the OFZ: attend accompanied (yes or no), meeting friends (always, sometimes, and never), meeting new people (yes or no), attended days (weekdays, weekend days, or both), how long have you attended the OFZ ( $>12$ months, between 1 and 12 months, or $<1$ month).

Perceived environment: proximity to residence (yes or no), accessibility (very easy, easy, hard, very hard), safety (do not want to say, not safe, or safe), presence of an exercise specialist (yes or no).

Built environment: trees and shade (yes or no), bike rack (yes or no), type of area (commercial or residential), designated area for walking/running (yes or no), and sports courts (yes or no).

Importantly, the level of the variables of conservation of the OFZ equipment, instructional panel, and easy to park the car were not analyzed because these characteristics were observed at all OFZs where users were interviewed.

\section{Statistical analysis}

Descriptive statistics were used to describe the OFZ users' profile and the independent variables (mean and standard deviation for continuous variables and proportion analysis for categorical variables). Poisson regression was used to examine the association between the outcome variable (volume of utilization higher than $90 \mathrm{~min}$ per week) with the collection of independent variables, using a robust adjustment for the variances. First, we conducted all bivariate analysis and then the multivariate analysis in order to define the final model of association. Before performing the adjusted analysis, the distributions of independent variables were tested against each other, with a confidence level of $95 \%$, noting that the variables were not homogeneous. Therefore, there would be no possible influences between the variables. All variables in the bivariate analysis with a p-value $<0.20$ in Wald's test were included in the multivariate analysis ${ }^{17}$. The order of inclusion in the multivariate model was based on the pvalue observed in the raw analysis, using the step forward method as the criterion method. After verifying the associations and adjustments, the final tested model comprised eight independent variables (days attended, meeting new people, meeting friends, physical activity level, designated area for walking/running, presence of an exercise specialist, how long attended the OFZ, and perceived health). Data were analyzed using SPSS version 24 (IBM Corporation, Armory, N.Y) and significance was set at $\mathrm{p}<0.05$. 


\section{Results}

Detailed information on the number of participants included for each OFZ is provided in Figure 1. A total of 190 individuals were approached in the nine OFZs in the city of Uberaba, Brazil. Forty-three out of 190 were not interviewed (17 refused to participate and 25 were not users of the OFZ). This yielded a total of 148 interviewed individuals ( 87 females and 61 males) for the study. During the data collection period, there were no rainy days and one holiday was replaced by the following day.

Detailed information on the environmental characteristics where the OFZs were installed, as well as the profile of the users, is given in Table 1. Briefly, no users were found in three out of the nine selected OFZs on the scheduled days and times proposed for the interviews. In five of the remaining six, the majority of the users were female, with an average monthly income above BRL 1,000.00. Leisure-time physical activity ranged from 88.5 to 353.9 min per week.

All OFZs attended by the users had between 10 and 14 pieces of maintained/conserved equipment, with an information panel about the utilization of the equipment, and only one OFZ did not have adequate lighting. It was further observed that all OFZs had easy parking but the only one had an appropriate bike rack. In terms of the location of the OFZs, only one was in a non-residential area and three were installed in a space where there was also an option for walking/running (i.e., track) and sports courts (Table 1).

The three OFZs that did not have users on the days/ times scheduled for data collection had less equipment compared to the others (i.e., 6 to 9), no information panel, and no tracks or clear designated areas for walking or running. Furthermore, in two out of the three OFZs, the equipment was found to be poorly maintained (Table 1).

The descriptive characteristics of the OFZ users can be seen in Table 2. The descriptions indicate the total study sample participants $(\mathrm{n}=148)$ and the participants with OFZ volume utilization higher than $90 \mathrm{~min}(\mathrm{n}=67)$.

Table 3 displays in detail the regression analysis conducted to examine the association between the individual, environmental, and pattern of utilization variables with the dependent variable (weekly volume of utilization of the OFZ higher than $90 \mathrm{~min}$ ). Briefly, the bivariate analysis revealed that individual (i.e., perceived health as excellent and being classified as physically active during leisure time), the pattern of utilization of OFZ (i.e., meeting friends always, meeting friends sometimes, meeting new people, and attending the OFZ during the week and on weekend days), perceived environment (i.e., presence of an exercise specialist), and built environment (i.e., availability of a track [walking/running]) variables were significantly associated with a higher volume of utilization of these public spaces. The independent variables were not homogeneous with each other. The adjusted analysis

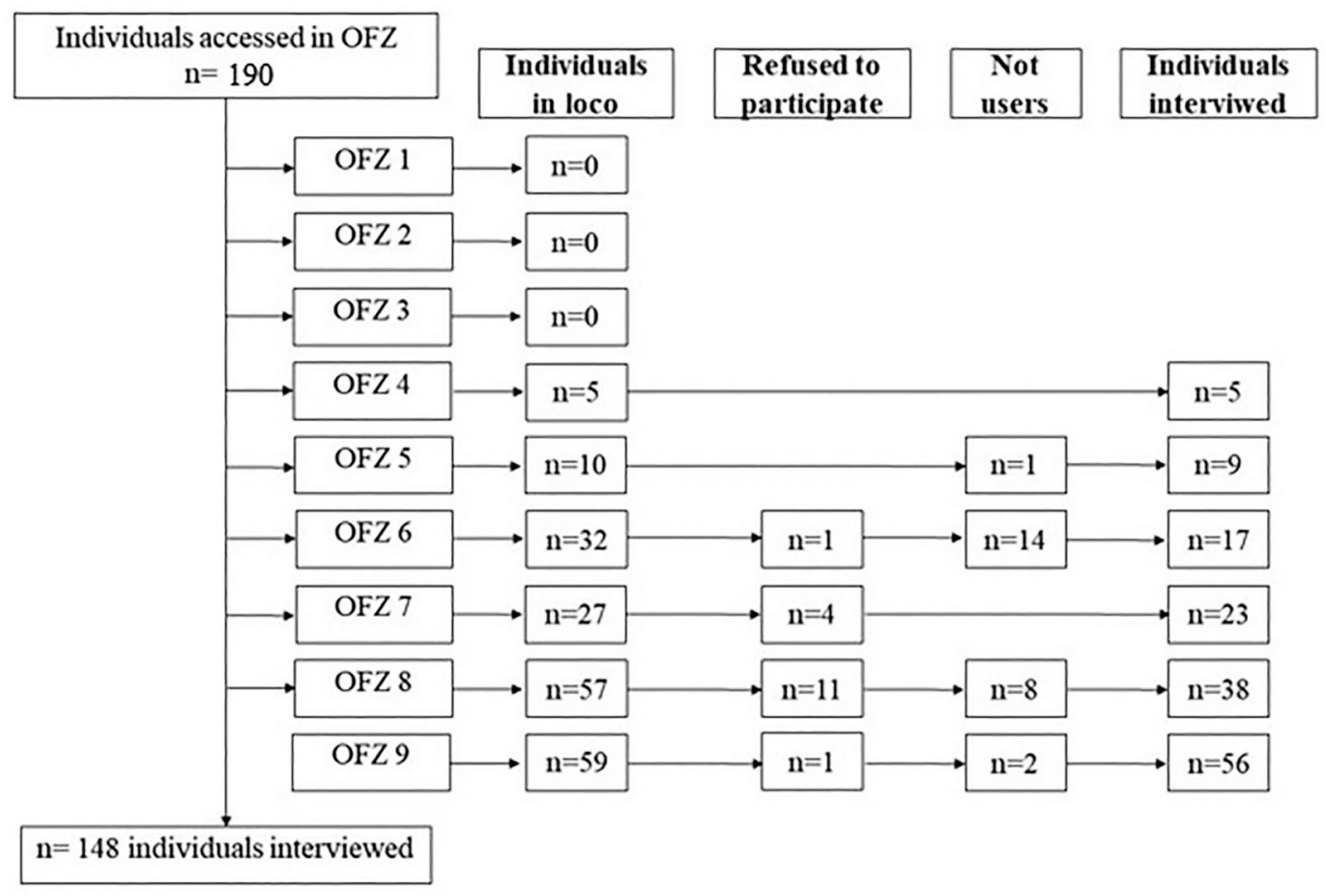

Figure 1 - Flow chart of the individuals included/interviewed in each outdoor fitness zone included in the study. OFZ= Outdoor Fitness Zone; OFZ1 = Praça Altamiro de Deus; OFZ = Praça Edgard F. da Silva; OFZ3 = Praça São Jorge; OFZ4 = Praça Hélio Fernandes de Oliveira; OFZ5 = Praça da Abadia; OFZ6 = Praça Dr. Jorge Frange; OFZ7 = Parque das Acácias; OFZ8 = Praça Pôr do Sol; OFZ9 = Praça G. M. Pinto. 
Table 1 - General characteristics of the outdoor fitness zone users and detailed characteristics of the environment where the outdoor fitness zone $(n=9)$ of the city of Uberaba, Brazil were installed.

\begin{tabular}{|c|c|c|c|c|c|c|c|c|c|}
\hline & \multicolumn{9}{|c|}{ Location of the outdoor fitness zones } \\
\hline & 1 & 2 & 3 & 4 & 5 & 6 & 7 & 8 & 9 \\
\hline $\mathrm{N}$ & 0 & 0 & 0 & 5 & 9 & 17 & 23 & 38 & 56 \\
\hline Female, $\%$ & - & - & - & 100 & 55.6 & 23.5 & 56.5 & 68.4 & 60.7 \\
\hline age, years & - & - & - & $51.4(6.9)$ & $64.1(6.9)$ & $65.2(10.8)$ & $52.6(12.7)$ & $50.0(14.6)$ & $53.9(12.6)$ \\
\hline Monthly Income (BRL) & - & - & - & $1,034.5(687.7)$ & $872.0(542.9)$ & $1,589.8(814.3)$ & $3,234.1(2,075.0)$ & $2,188.9(1,522.6)$ & $2,672.4(1,988.0)$ \\
\hline LTPA (min/week) & - & - & - & $146(102.0)$ & $99.4(90.1)$ & $88.5(98.4)$ & $275.7(172.0)$ & $353.9(313.5)$ & $230.4(116.2)$ \\
\hline Number of equipment & 6 & 6 & 9 & 12 & 14 & 12 & 13 & 11 & 10 \\
\hline Maintained equipment & No & Yes & No & Yes & Yes & Yes & Yes & Yes & Yes \\
\hline Information panel & No & No & No & Yes & Yes & Yes & Yes & Yes & Yes \\
\hline OFZ with lighting & Yes & No & Yes & Yes & No & Yes & Yes & Yes & Yes \\
\hline Presence of trees and shades & Yes & Yes & Yes & No & Yes & Yes & No & Yes & Yes \\
\hline Parking lot or easy access to & Yes & Yes & Yes & Yes & Yes & Yes & Yes & Yes & Yes \\
\hline Availability of bike rack & Yes & No & No & No & No & Yes & No & No & No \\
\hline Residential area & Yes & Yes & Yes & Yes & Yes & No & Yes & Yes & Yes \\
\hline Track availability & No & No & No & No & No & No & Yes & Yes & Yes \\
\hline Sport courts & No & No & Yes & Yes & No & No & Yes & Yes & No \\
\hline
\end{tabular}

Note: all values are mean and standard deviation unless otherwise noted.

LTPA: Leisure-time physical activity; BRL: Brazilian currency; OFZ: Outdoor Fitness Zone.

1 - Praça Altamiro de Deus; 2 - Praça Edgard F. da Silva; 3 - Praça São Jorge; 4 - Praça Hélio Fernandes de Oliveira; 5 - Praça da Abadia; 6 - Praça Dr. Jorge Frange; 7 - Parque das Acácias; 8 - Praça Pôr do Sol; 9 - Praça G. M. Pinto.

revealed that the following variables remained associated with a weekly volume of utilization of the OFZ higher than 90 min: meeting friends always $(P R=3.43 ; 1.61$ $7.34)$ and meeting friends sometimes $(\mathrm{PR}=2.43 ; 1.21$ 4.90), attending the OFZ only during the week and on weekend days ( $\mathrm{PR}=0.52 ; 0.37-0.73)$, and no availability of a track for walking or running $(\mathrm{PR}=0.48 ; 0.23-0.99)$.

\section{Discussion}

The present study examined the association between the weekly volume of utilization of OFZs with individual and environmental characteristics, as well as with the utilization pattern of these public spaces in the city of Uberaba, Brazil. The findings were: a significant association between volume of utilization of the OFZ higher than 90 min (dependent variable) with meeting friends, visiting the OFZ during the week and on weekend days, and availability of an area (i.e., track) for walking/running at the location. Because no individual variables were associated with the volume of utilization of the OFZ, our findings partially confirm our hypothesis.

We observed that users of three out of the nine assessed OFZs reported engaging in over $150 \mathrm{~min}$ per week of leisure-time physical activity. These findings corroborate the results of previous studies conducted in different states of Brazil. For instance, in Florianópolis, $73.2 \%$ of the users reported engaging in $\geq 150 \mathrm{~min}$ per week of physical activity with the help of the OFZ. In Pelotas, nearly $78 \%$ of the OFZ users in the city are considered to be physically active because of the availability of this public environment. Similarly, $41 \%$ of users are considered physically active because of the use of this environment in João Pessoa ${ }^{18,19}$. One study conducted in the United States demonstrated that the installation of OFZs in public parks increased the utilization of these places and the frequency of physical activity was reported to be higher among users compared to non-users where the OFZs were installed ${ }^{20}$. Collectively, it is suggested that OFZs may be important places to conduct studies that could help in the development of public policies targeting the utilization of such spaces. There is preliminary evidence in Brazil showing an association between OFZ utilization with physical activity level ${ }^{21}$.

Among the OFZs observed/evaluated, the three presenting a higher presence of users presented similar environmental characteristics, such as well-maintained equipment, an information panel, lighting, availability of a parking lot, or easy access to parking, located in a residential area, and spaces for walking. Three OFZs did not have users at the scheduled days/times for the interviews. These presented less equipment than the others visited in the study; with equipment not being well-maintained in two out of the three. Furthermore, these two OFZs did not have an information panel and were installed in a place that did not offer a space for walking/running. The good condi- 
Table 2 - Descriptive characteristics of OFZ users discriminated by a total sample of study participants $(\mathrm{n}=148)$ and participants with OFZ volume utilization higher than $90 \mathrm{~min}$.

\begin{tabular}{|c|c|c|c|c|c|}
\hline & \multirow[t]{2}{*}{ Variables } & \multicolumn{2}{|c|}{ Total sample of study participants } & \multicolumn{2}{|c|}{$\begin{array}{l}\text { Participants with OFZ volume } \\
\text { utilization higher than } 90 \text { min }\end{array}$} \\
\hline & & $N=148$ & $\%$ & $N=67 *$ & $\%$ \\
\hline \multirow[t]{2}{*}{ Sex } & Females & 87 & 58.8 & 40 & 59.7 \\
\hline & Males & 61 & 41.2 & 27 & 40.3 \\
\hline \multirow[t]{3}{*}{ Age, years } & Up to 45 & 41 & 27.7 & 18 & 26.9 \\
\hline & 46 to 60 & 58 & 39.2 & 27 & 40.3 \\
\hline & 60 and over & 49 & 33.1 & 22 & 32.8 \\
\hline \multirow[t]{5}{*}{ Marital status } & Married & 89 & 60.1 & 38 & 56.7 \\
\hline & Single & 20 & 13.5 & 10 & 14.9 \\
\hline & Widow & 14 & 9.5 & 6 & 9.0 \\
\hline & Divorced & 14 & 9.5 & 8 & 11.9 \\
\hline & Living with partner & 11 & 7.4 & 5 & 7.5 \\
\hline \multirow[t]{2}{*}{ Children } & No & 24 & 16.2 & 11 & 16.4 \\
\hline & Yes & 124 & 83.8 & 56 & 83.6 \\
\hline \multirow[t]{4}{*}{ Education attainment } & No or incomplete elementary school & 30 & 20.3 & 13 & 19.4 \\
\hline & Complete elementary school & 30 & 20.3 & 13 & 19.4 \\
\hline & Complete high school & 60 & 40.5 & 25 & 37.3 \\
\hline & College graduated & 28 & 18.9 & 16 & 23.9 \\
\hline \multirow{4}{*}{$\begin{array}{l}\text { Income, number } \\
\text { of minimum wages* }\end{array}$} & Up to 1 & 38 & 25.9 & 15 & 22.7 \\
\hline & More than 1 and up to 2 & 35 & 23.8 & 20 & 30.3 \\
\hline & More than 2 and up to 5 & 40 & 27.2 & 15 & 22.7 \\
\hline & More than 5 and up to 10 & 34 & 23.1 & 16 & 24.2 \\
\hline \multirow[t]{2}{*}{ Chronic diseases } & No & 75 & 50.7 & 35 & 52.2 \\
\hline & Yes & 73 & 49.3 & 32 & 47.8 \\
\hline \multirow[t]{3}{*}{ Perceived health } & Excellent & 15 & 10.1 & 10 & 15.0 \\
\hline & Very good & 47 & 31.8 & 23 & 34.3 \\
\hline & Good & 86 & 58.1 & 34 & 50.7 \\
\hline \multirow[t]{2}{*}{ Commuting mode } & Active & 125 & 84.5 & 57 & 85.1 \\
\hline & Passive & 23 & 15.5 & 10 & 14.9 \\
\hline \multirow[t]{2}{*}{ PA level } & Physically active & 101 & 68.2 & 55 & 82.1 \\
\hline & Insufficiently active & 47 & 31.8 & 12 & 17.9 \\
\hline \multirow{2}{*}{$\begin{array}{l}\text { PA engagement before } \\
\text { the OFZ }\end{array}$} & No & 82 & 55.4 & 37 & 55.2 \\
\hline & Yes & 66 & 44.6 & 30 & 44.8 \\
\hline
\end{tabular}

Note: *Monthly income; PA: physical activity; OFZ: Outdoor Fitness Zone.

tions of the OFZ neighborhoods possibly increased the use of these places. OFZs may contribute to making urban areas more livable and safer, enabling the use of public spaces in the cities where they are installed ${ }^{11}$. Moreover, only one of the two had a sports court. Of the environment variables (perceived and built) included in the bivariate analysis, the absence of an exercise specialist and the presence of designated areas for walking/running were associated with a higher volume of utilization of the OFZ.
However, in the adjusted analysis, only the presence of designated areas for walking/running remained associated with the volume of utilization above 90 min per week. There is evidence to suggest that places with infrastructure to allow people to engage in walking and near to their neighborhood may positively impact the physical activity behavior of users ${ }^{12}$. Thus, the combination of an OFZ and other options for physical activity engagement in residential areas should be considered in the implementation of an 


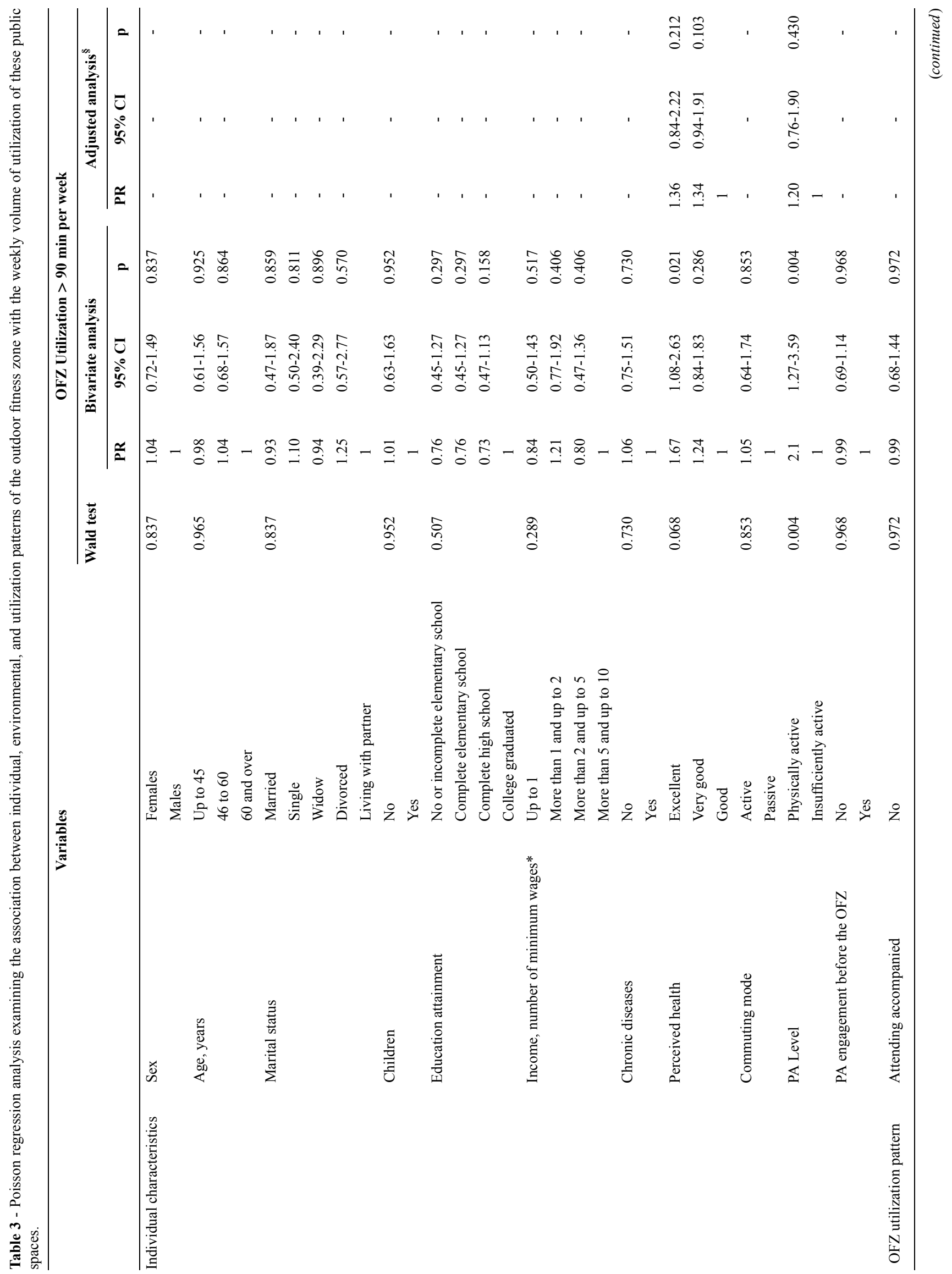




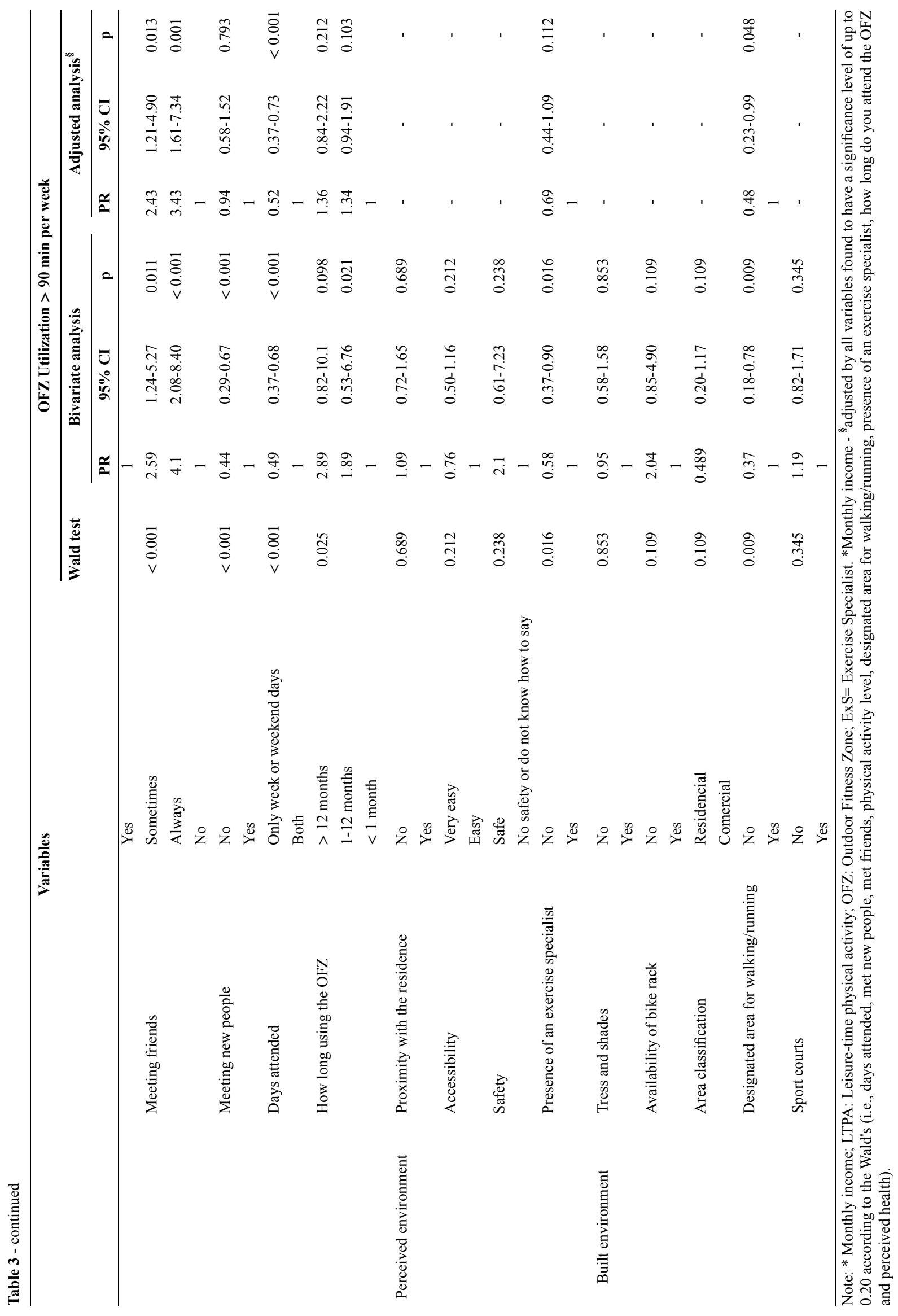


OFZ, as this combination may result in higher adherence by users.

Even though the variable presence of an exercise specialist did not remain associated with the volume of utilization of the OFZ for more than 90 min per week, it is important to highlight that $91 \%$ of OFZ users reported not receiving professional guidance at the OFZ. The presence of the exercise specialist was observed only on one day/ time during data collection (7:00-8:00 AM) and only at one OFZ; where eight users were interviewed. Although the equipment is easy to use, the presence of an exercise specialist could encourage participation, mainly in places with a lower number of users. This could be attractive to encourage more people to utilize the OFZs safely and correctly and to advise them on how to use the equipment and perform the exercises.

This finding may be related to self-efficacy, an important element in physical activity behavior. According to researchers, self-efficacy is an important variable that helps explain short- and long-term engagement in physical activity. Individuals reporting higher levels of self-efficacy are more likely to maintain a physically active lifestyle in the future ${ }^{22}$.

Attending the OFZs to meet friends (i.e., always, or sometimes) and during the week and on weekend days were associated with a higher volume of utilization of the OFZ. The association observed for the variables meeting friends always and sometimes corroborates the findings observed by Fermino et al. (2012) ${ }^{21}$. In that study, the authors observed a positive association between visiting parks accompanied and physical activity engagement. Social support from friends and family has a positive impact on one's physical activity. To this end, it is important to develop environments that stimulate social interactions in order to foster opportunities for people to develop meaningful social relationships that may result in physical activity engagement ${ }^{16}$. In general, OFZs contribute to equity in access to physical activity ${ }^{23}$.

In terms of OFZ utilization, we observed that the majority of the users in our study reported attending the OFZ only during the week or only on weekend days, not both. This is somewhat different from what was described by Cohen et al. $(2012)^{20}$. However, when observing users who reach more than 90 min of use per week, most of them attend the OFZ both during the week and on weekend days. The significant association found in our study suggests that users attending the OFZ either during the week or on weekend days are more likely to report a volume of utilization lower than 90 min per week.

Although important, our results should be interpreted with caution due to some limitations. Our study was not based on power analysis. The study employed questionnaires specifically to avoid long interviews, however, the questionnaires were not validated (except for the IPAQ). It is important to highlight that there is a paucity of instruments developed to specifically assess the physical environment (i.e., natural or built) in parks that could be used to the Brazilian reality. Studies making use of the System for Observing Play and Recreation in Communities (SOPARC) have assessed more complex variables (e.g., estimation of physical activity or exercise intensity); which has been demonstrated to be an acceptable instrument of evaluation ${ }^{16,24}$. Thus, we do not consider that the observation of variables that are specific to the environment, which are normally objective (e.g., presence of an information panel, presence of parking lot, and sports court) is a limiting factor. Regarding the less objective variables (lighting, trees, and shade, residential or commercial area) the interviewers were trained, which mitigated subjectivity in their assessment. Another possible limitation is related to the days/times scheduled for visiting the OFZs. Although we used a variety of days and times to potentially guarantee diversity in the sample, likely some users did not have the chance to be interviewed as they attended the OFZ on days/times not included in our schedule. This is reinforced by the fact that in three out of nine OFZs visited (with less favorable environmental characteristics) our interviewers did not observe any users on the days/times scheduled. This may have affected the analysis of the association with environmental variables. Thus, future studies should be conducted without the in loco approach. Despite the limitations, this study provides valuable information on potential variables that may be targeted to promote OFZ use and, consequently, physical activity.

\section{Conclusion}

Our findings demonstrated that environmental characteristics (i.e., no availability of areas to walk/run) are associated with the volume of utilization of fewer than 90 min per week of the OFZ. Utilization patterns (i.e., meeting friends always and/or sometimes, and attending the OFZ both during the week and on weekend days) were associated with a volume of utilization of the OFZ of higher than 90 min per week. In terms of the individual characteristics, none of the assessed variables were found to be associated with the utilization volume of the OFZ after the adjusted analysis. In the city of Uberaba, Brazil utilization of OFZs to engage in physical activity during leisure-time may be an effective strategy to improve the physical activity level of users when installed in places where other options for physical activity engagement are present. To this end, the findings of the present study may help in the development of strategies and public initiatives focusing on physical activity promotion through the utilization of OFZs in the city of Uberaba, Brazil, as well as in cities with similar characteristics. 


\section{Acknowledgments}

The authors thank the Coordenação de Aperfeiçoamento de Pessoal de Nível Superior (CAPES) for the scholarship provided to Debora Bernardo during her master's studies and Dr. Clayton Camic from the Department of Kinesiology and Physical Education of Northern Illinois University for proofreading the manuscript.

\section{References}

1. Kohl HW, Craig CL, Lambert EV, Inoue S, Alkandari JR, Leetongin $\mathrm{G}$, et al. The pandemic of physical inactivity: global action for public health. Lancet. 2012;380:294-305. doi

2. Guthold R, Stevens GA, Riley LM, Bull FC. Worldwide trends in insufficient physical activity from 2001 to 2016: a pooled analysis of 358 population-based surveys with 1.9 million participants. Lancet. 2018;6:1077-86. doi

3. World Health Organization. WHO guidelines on physical activity and sedentary behaviour: at a glance. Geneva: World Health Organization; 2020.

4. Ding D, Lawson KD, Kolbe-Alexander TL, Finkelstein EA, Katzmarzyk PT, Van-Mechelen W, et al. The economic burden of physical inactivity: a global analysis of major noncommunicable diseases. Lancet. 2016;388:1311-24. doi

5. Lee I-M, Shiroma EJ, Lobelo F, Puska P, Blair SN, Katzmarzyk PT, et al. Effect of physical inactivity on major noncommunicable diseases worldwide: an analysis of burden of disease and life expectancy. Lancet. 2012;380:219-29. doi

6. Sallis JF, Cervero RB, Ascher W, Henderson KA, Kraft MK, Kerr J. An ecological approach to creating active living communities. Annu Rev Public Health. 2006;27:297322. doi

7. Palácios AROP, Salineiro AP dos SB, Nardi ACF, Rosaneli CF. A concepção do Programa Maringá Saudável, suas ações e resultados. Divulg saúde debate. 2009;34-40.

8. Souza C, Fermino R, Añez C, Reis R. Perfil dos frequentadores e padrão de uso das academias ao ar livre em bairros de baixa e alta renda de Curitiba-PR. Rev Bras Ativ Fís Saúde. 2014;19:86-97. doi

9. Alberico CO, Hipp JA, Reis RS. Association between neighborhood income, patterns of use, and physical activity levels in fitness zones of Curitiba, Brazil. J Phys Act Health. 2019;16: 447-54. doi

10. Bergmann GG, Streb AR, Ferrari M, Alves DCC, Soares BAC, Ferreira GD, et al. The use of outdoor gyms is associated with women and low-income people: a cross-sectional study. Public Health. 2021;190:16-22. doi

11. Fernández-Rodríguez EF, Merino Marban R, RomeroRamos O, López-Fernández I. A systematic review about the characteristics and patterns of use of outdoor gyms. J Hum Sport Exerc. 2020;15:471-80. doi

12. Copeland JL, Currie C, Walker A, Mason E, Willoughby TN, Amson A. Fitness Equipment in Public Parks: Frequency of Use and Community Perceptions in a Small Urban Centre. J Phys Act Health. 2017 May;14(5):344-352. doi
13. Instituto Brasileiro de Geografia e Estatística. Uberaba, MG. Available from: https://cidades.ibge.gov.br/brasil/mg/uber aba/panorama [Accessed $3^{\text {rd }}$ March 2021]

14. Parque das Acácias. Uberaba, MG. Available from: http:// www.uberaba.mg.gov.br/portal/conteudo,634 [Accessed $3^{\text {rd }}$ March 2021]

15. Matsudo S, Araújo T, Matsudo V, Andrade D, Andrade E, Oliveira LC, et al. Questionário internacional de atividade física (IPAQ): estudo de validade e reprodutibilidade no Brasil. Rev Bras Ativ Fís Saúde. 2001;6:5-18. doi

16. Parra DC, McKenzie TL, Ribeiro IC, Hino AAF, Dreisinger $\mathrm{M}$, Coniglio $\mathrm{K}$, et al. Assessing physical activity in public parks in Brazil using systematic observation. Am J Public Health. 2010;100:1420-26. doi

17. Hosmer D, Lemeshow S. Applied logistic regression. $2^{\text {nd }}$ ed. Hoboken, Wiley Online Library; 2000.

18. Moura-Junior JS, Ferreira DKS, Martins MO, Lima NMM. Nível de atividade física e perfil sociodemográfico dos usuários dos ambientes públicos de atividades físicas na cidade de João Pessoa-PB. Rev bras Ciênc Saúde. 2011;15:349-56.

19. Silva MC da, Iepsen AM, Caputo EL, Engers PB, Spohr CF, Vilela GF, et al. Leisure-time physical activity and associated factors in fitness zones. Rev Bras Cineantropom Desempenho Hum. 2017;19:185-95. doi

20. Cohen DA, Marsh T, Williamson S, Golinelli D, McKenzie TL. Impact and cost-effectiveness of family fitness zones: a natural experiment in urban public parks. Health Place. 2012;18:39-45. doi

21. Fermino RC, Reis RS, Cassou AC. Individual and environmental factors associated with park and plaza use in adults from Curitiba, Brazil. Rev Bras Cineantropom Desempenho Hum. 2012;14:377-389. doi

22. Wójcicki T. Maintenance of physical activity interventions: premises of efficacy individual. REFACS. 2014;2(2):194199.

23. Mathias NG, Melo Filho J, Szkudlarek AC, Gallo LH, Fermino RC, Gomes ARS. Motivos para a prática de atividades físicas em uma academia ao ar livre de Paranaguá-PR. Rev. Bras. Ciênc. Esporte. 2019; 41; 222-228. doi

24. Hino AAF, Reis RS, Florindo AA. Built environment and physical activity: a brief review of evaluation methods. Rev Bras Cineantropom Desempenho Hum. 2010;12:387-94. doi

\section{Corresponding author}

Debora Bernardo da Silva.

E-mail: deborabernardo.silva@yahoo.com.br.

Manuscript received on December 14, 2020

Manuscript accepted on August 17, 2021

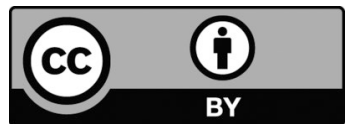

Motriz. The Journal of Physical Education. UNESP. Rio Claro, SP, Brazil - eISSN: 1980-6574 - under a license Creative Commons - Version 4.0 